\title{
correspondence
}

\section{Science with public appeal}

SiR,-I think your criticism of the BBC's programme, The Key to the Universe (3 February, page 393) was unfair to say the least. Nigel Calder did not make any "fundamental mistakes", especially in underestimating the serious mindedness of the audience. Indeed his refreshing attitude encourages the public to take a greater interest in science--we would soon fall asleep (at least 1 would) if the programme was presented in the way you implied in the article. 'these two-hour programmes are occasional: they are not the same as Horizon and they add a new look to the debate.

$I$ think you are making the fundamental error by assuming that "the uninitiated $99.9 \%$ of the audience can only have been thoroughly confused ...". I did not find the order in which the programme was presented at all confusing. Your leader writer should watch it again as a member of the public and not as a cynical critic.

\section{Harrogate, UK}

G. MARKS

SIR-In your editorial, "That was the weak force, that was" (3 February 1977), you make a strong criticism of Nigel Calder's two-hour BBC2 brainteaser, "The Key to the Universe." You ask, in effect, not only whether it was worth the resources devoted to it, but also whether it might not contribute to the further alienation of many people from science.

These are important questions to which we have no answer. In this regard the BBC fails us entirely. We are not told how much in financial terms such a two-hour programme costs; we do not know whether the key criterion of 'worth' may not be measured solely by audience ratings; and we are completely in the dark about the effect of such programmes on the general viewing audience. That Calder's book of the same title is high in the Sunday Times best-seller list tells us nothing about the TV programme except that it surely helps to sell the book.

The non-scientists with whom I watched the programme confessed that apart from the presentation of the 'black holes,' they were baffled. I found the jargon familiar, but I disagreed with some of Calder's emphases. I think he made too much of the tentative, of the as-yet unaccepted, as in Salam's exposition for example. In that sense, it was difficult to distinguish the 'real' from the 'unreal.'

I have said before that the populariser of science, as he functions today, cannot disseminate the subtle ideas of science; that these really cannot be understood without hard, disciplined effort. We need a research programme on this thesis. The BBC (and ITV) might consider funding that part of it concerned with the presentation of science on TV and radio. Such a proposal concerns the key question of what the presenters of science are really providing, not only in terms of good, entertaining viewing, but also in their contribution to general understanding en route to involving thep ublic in decision-making about the use and impact of science in everyday life. Savile Club, London Maurice Goldsmith

\section{Tidal energy}

SIR-Your leading article (10 February 1977) refers to the 'severe defect' of the periodicity of the tides being not always in phase with the daily load cycle, but nearly $40 \%$ of our electrical energy is used for space and water heating where the 'defect' is not at all severe. The use of blocks of tidal energy produced in regular and predictable amounts, both in time and quantity, is now perfectly feasible in the British system, and as installed capacity increases (if indeed it does increase), will become easier rather than harder to absorb. This is without the addition of any further pumpedstorage capacity.

The reasons why the French have not proceeded with the Iles de Chausey scheme have nothing to do with the foregoing point, since La Rance incorporates a pumped-storage capability to provide power capacity in phase with peak-demand-if that is what the operators require. (Incidentally La Rance is presently using peaking system energy to pump on those occasions when so doing produces more energy overall.) The reasons are both economic and oceanographic, since the inclusion of sophisticated pumpedstorage facilites made La Rance so expensive as to discourage further investment in tidal energy, coupled with fears that a much larger scheme might have reduced the tidal range.

The defects of pumped-storage in estuarial schemes are primarily cost, since such facilities can be provided more cheaply on land (as at Ffestiniog or Dinorwic) or underground, and secondly because the important function of system spinning reserve is unavailable from a tidal pumped-storage plant without loss of available energy. The arguments are all developed in the technical literature and it behoves your leader writer to give it more than a cursory examination before committing himself to a particular solution.

The proposed Severn scheme your article describes is one of at least six proposals made in the last few years, all of which deserve examination in the light of system requirements. It will do the cause of tidal energy no good if a scientific journal of your reputation appears to be prejudging the solution to what is a most complex problem.

E. M. WILSON

Department of Civil Engineering

University of Salford, UK

\section{Geothermal electricity}

Sir-Recent studies of potential UK geothermal heat sources (for example, Oxburgh Nature 262, 526; 1976) have been virtually unanimous in stating that temperatures greater than $200{ }^{\circ} \mathrm{C}$ would be required from sources intended for electricity generation. A report produced by Patscentre International has shown that, contrary to this general view, it may well be possible to accept a much lower temperature limit. If it can be combined with a fossil-fuel source in an existing or purpose-built power station, geothermal heat in the temperature range of $100-200{ }^{\circ} \mathrm{C}$ could be economically used for electricity generation.

In modern steam plarts most of the feedwater heat is supplied by low-

\section{Correction}

A bad telephone line helped to produce three errors in the article "Give us a call, says NASA' (10 March, page 112). The Viking chief project scientist is Dr Gerald A. Soffen, not Dr Soffes; the Kioto meeting will be in the first week of April, not in June, and will be organised by the International Society for the Study of the Origin of Life; and the Tel Aviv meeting in June is the COSPAR and not the pulsar meeting. Sorry. 
temperature steam from the turbines. However, this steam, which in a conventional station has been heated by a high-grade fossil fuel, is diverted from work-producing duties in the turbine. If low-grade geothermal heat is used for feedwater heating, the steam could be retained in the turbine, thus increasing both the work output and the cycle efficiency relative to the fossil fuel. The resulting capitalised fuel saving (for the normal rated output) can then be used to pay for the necessary geothermal plant. (I have discussed a similar use for lowgrade waste heat in MHD power generation in Energy Conversion 8 177 ; 1968.) The amount of geothermal heat that would be usable in this system, which could be applied to either an existing or a purpose-built station, is no more than about $15 \%$ of the total heat input; that is, about $200 \mathrm{MW}(\mathrm{t})$ could be accepted by a $500 \mathrm{MW}(\mathrm{e})$ steam plant using geothermal heat at $125^{\circ} \mathrm{C}$. This would give a fossil-fuel saving of $5 \%$.

An alternative purpose-built combined plant, in which the geothermal heat predominates, would use fossil fuel for superheating only. In this case, efficiencies in the region of $100 \%$ (relative to the fossil fuel) become possible. For example, $100 \mathrm{MW}(\mathrm{e})$ output could be obtained from $100 \mathrm{MW}(\mathrm{t})$ fossil fuel combined with $360 \mathrm{MW}$ of geothermal heat at $185^{\circ} \mathrm{C}$. This method also has the advantage of low steam wetness, thus appreciably neducing turbine blade erosion, which could occur in a plant that is predominantly geothermal.

The cost benefit analysis proceeds as follows. The present saving on fossil fuel is determined from an annuity-type calculation, taking into account, among other factors, the current fuel cost, inflation of real cost of fuel, interest rate, plant life-time, and increased load factor allowed by increased efficiency.

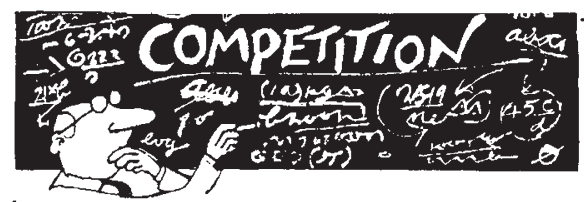

\section{Competition 12.}

A chair in bio-aeronautics has recently been established in the UK. Its occupant is an expert in crop spraying. $£ 10$ for the best real or fictitious professorial title. Entries by 20 April to Competition 12, Nature.

Competition 11. Readers' contributions offered humorous associations with the work of scientists. Thus: 'Faraday was incapacitated', and so on through a deluge of awful puns. Jim
Thus a capital allowance (per kilowatt of geothermal power) is obtained which can be compared with estimated specific costs of geothermal plant for various conditions.

Results for a purpose-built plant based on a modern conventional power station illustrate the operation of the first system. With the plant situated on hot dry rock supplying feedwater heat at $125^{\circ} \mathrm{C}$, a fossil fuel cost of $9 \mathrm{p}$ a therm, and a load factor of $80 \%$, the capitalised fuel saving over 20 years, with a basic interest rate of $10 \%$ a year, is $£ 62$ per kilowatt of geothermal power. This equals the (1974) cost of the associated geothermal plant (wellhead equipment and so on) calculated from fairly conservative data supplied by the Energy Technology Support Unit (Harwell) for a site having a temperature gradient of $45^{\circ} \mathrm{C}$ per $\mathrm{km}$. For a similar station situated on an aquifer, the available cost of $£ 62$ per $\mathrm{kW}(\mathrm{gt})$ would pay for geothermal plant in the upper half of the range of calculated aquifer costs. Of course, the capitalised fuel saving increases with the fossil-fuel cost, the fuel inflation rate (in real terms), and the load factor. Figures for the second type of plant, using $185^{\circ} \mathrm{C}$ geothermal heat, show that its unit electricity costs are comparable with those of conventional power stations.

The Patscentre study has shown that geothermal sites that coincide with, or are accessible to, fossil-fuel sources could be of special interest for electricity generation. For instance, the nearness of the Durham hot rocks (granite) to the Durham coal fields should be noted, and coastal sites on the Hampshire sedimentary basin could also be of interest.

\section{Patscentre International, $U K$}

\section{Management courses}

Sir,--I have long felt it appropriate that the likeness that accompanies
Kenneth Mellanby's articles should be as black and white as the views he expresses! However, the truth about management courses for scientists may not be quite as black as his article ( 3 March, page 11) might suggest. Five years ago A. J. Lockwood and I started a course in research management ( $R \& D$ Management 5, 235-238; 1975) for heads of research sections at the Building Research Establishment. It has been held annually since then and now draws participants from a wide range of government research laboratories (both civil and defence). Those who attend appear to find it helpful.

The course was started because many section heads felt the need for some help with the management aspects of their work, a need that was understandably not met by the more general management courses that were then available-and it may be that Professor Mellanby's strictures were directed at such courses. Our courses are deliberately designed for those leading research teams. Perhaps the secret of whatever success the courses have achieved lies in the very fact that we deliberately refrain from any attempt at 'training'. Rather, we try to make available to participants a wide range of conceptual material and practical experience on which they can draw for use in their own circumstances. More important still, we devote about half the course time to fostering, within a carefully thought out series of syndicate exercises, the exchange of the management experience that participants will have accumulated during their working lives. Just as scientists profit considerably from an exchange of their scientific experience, we have found that they can and do receive considerable benefit from an exchange of their (often unrecognised) management experience.

\section{K. Alsop}

Building Research Establishment, Garston, Watford, UK
Watson, according to most competitors, had a guess-what in his neck. Two winners, one brief, one less so.

Brähe thought the paper by Copernicus revolutionary, but pointed out that his argument was essentially circular (M. C. Thorne, Harwell, UK).

On the first day Rutherford reported an immediate disintegration of the Symposium catalysed by Brønsted's acidic comments on Madame Curie's radiant attire. Drs Barnard and DeBakey were further disheartened when Van de Graaff generated a separate reaction from Schiff by referring to her attire as basically colourless. Bragg viewed things from another angle as did Roentgen who saw through it all. Compton recoiled at the prospect of making any statement while Planck and deBroglie also went to some lengths not to make waves-an attitude that Moseley called uncharacteristic. Wegener asserted that if the rifts continued to grow things would drift further apart. As usual, Heisenberg was uncertain but Coulomb and Nobel were positive that such a charged situation was potentially explosive. Kelvin and Boyle advised that a cooling-off period might reduce the pressures that were building up. Bell thus called on Hubble and Doppler to focus their attention on shifting the emphasis to a series of higherlevel discussions as earlier suggested by Balmer and Lyman. Newton seconded the motion and, being short of time, Einstein tried to apply a constant and massive attempt to bring the entire matter to a close. The following day Watson and Crick happily reported that things were taking a turn for the better. (K. M. Towe, Smithsonian Institution, Washington, USA). 